\title{
Instinto queer y escenas camp en Arsène Schraurwen de Olivier Schrauwen
}

\author{
Queer instinct and campscenes in \\ Arsène Schrauwen by Olivier Schrauwen
}

Mara González de Ozaeta

Mara González de Ozaeta es doctora cum laude en Estudios Literarios por la Universidad Complutense de Madrid. Su tesis doctoral trataba sobre los aspectos de la autenticidad y el efecto de esta poética, así como de los diversos recursos de repetición en las canciones y performances de Bob Dylan. Licenciada en Filología Inglesa por la misma universidad, escribe sobre cómic y feminismo en su página web Ángulo Crítico y en medios especializados, como la revista Mincho, La Tribu o Tebeosfera.

Fecha de recepción: 9 de mayo de 2019

Fecha de aceptación definitiva: 13 de noviembre de 2019 


\title{
Resumen
}

Este artículo estudia los aspectos queer y camp en Arsène Schrauwen (2014) de Olivier Schrauwen. El autor utiliza el artificio, la parodia y el vínculo entre narración gráfica y convencional para representar sexualidades alternativas y turbaciones propias del cuestionamiento histórico y la dominación masculina.

En Contra la interpretación (1969), Susan Sontag nos invita a ignorar la exégesis tradicional para hacer una erótica del texto. Gracias a que Olivier Schrauwen vincula erotismo y lectura, puede analizarse como lo hubiera querido la ensayista estadounidense. Además, lo camp desarticula el dominio de la lógica, la ética y los patrones estéticos constituyéndose al margen de la alta cultura y estableciendo el epítome de la libertad creadora: esa ciudad ideal que el imperio del hombre occidental desea conquistar.

Palabras clave: Camp, erotismo, narración, Olivier Schrauwen, queer

\begin{abstract}
This essay studies queer and camp aspects within Olivier Schrauwen's Arsène Schrauwen (2014). The author uses artifice, parody and the union between the graphic and conventional narration to represent alternative sexualities and the typical concerns of historical questioning and masculine domination.

In Against Interpretation (1969), Susan Sontag invites the reader to ignore the traditional exegesis and replace it for an erotic of the text. Olivier Schrauwen's effort connecting erotism and the pleasure of reading facilitates an analysis as the American essayist would have liked. In addition, the camp dismantles logics, ethics and aesthetic dominion by establishing the text away from high culture's scenery and signifying the epitome of the creator's freedom: the ideal settlement that men's empire want to conquer.
\end{abstract}

Keywords: Camp, erotics, narration, Olivier Schrauwen, queer

\section{Cita bibliográfica}

González de Ozaeta, M. «Instinto queer y escenas camp en Arsène Schrauwen de Olivier Schrauwen», en CuCo, Cuadernos de cómic, n.o 13 (2019), pp. 7-26. 


\section{Introducción}

Este texto persigue acercarse a aquello que la ensayista Susan Sontag ${ }^{1}$ establecía como prioritario en la crítica literaria; es decir, en lugar de realizar una hermenéutica del texto en busca de la verdad y la coherencia, plasmar una erótica del arte. Su método es atractivo y asume la cualidad de un reto crítico precisamente porque, al igual que la novela en sí misma, se aleja de la dimensión simbólica de la dominación masculina, según Bordieu. ${ }^{2}$ Se trata, como continúa explicando el antropólogo francés, de realizar la difícil tarea de huir de las estructuras históricas del orden masculino - algo que, por otro lado, la narración de Olivier Schrauwen, el autor de este cómic, también lleva a cabo-. Con una «erótica del arte», Sontag no se refiere a una poética del erotismo - sobre cómo se representa lo erótico en el lenguaje artístico- si no que prefiere analizar los procesos artísticos y estéticos en códigos eróticos. Esto está patente a lo largo de esta autoficción gráfica que podría resumirse como una masturbación en sí misma o un ejercicio del poder autoral; un deseo de volver a la figura, no ya del padre, sino del abuelo, para extender el concepto de origen o herencia y meter el dedo en el fondo, desapareciendo la intención autoral, pero no del todo.

Roland Barthes se refería al placer del texto como un placer edípico - despojarlo de su cubierta, conocerlo, aprender su origen y su fin-.${ }^{3} \mathrm{El}$ cómic del cual aquí se trata se concibió inicialmente como un tríptico, aunque esta autora se refiere a la versión integral. ${ }^{4}$ En este caso, el autor propone directamente a los lectores rupturas o descansos de la lectura continua implícita en el volumen. Lo hace con avisos como «Por favor, deja que pase una semana antes de comenzar» - entre los capítulos 1 y 2 -, «Por favor, deja que pasen dos semanas antes de continuar» - entre el 2 y el 3-y «Gracias por haber esperado», quizá destinados a que nuestros sentidos sigan igual de despiertos que al principio. En muchos aspectos, Olivier Schrauwen hace ejemplares esfuerzos por reasignar una ruta mas placentera a la lectura del cómic. Me pregunto entonces, abocada a no obtener una respuesta definitiva, si leer puede parecerse a una experiencia erótica.

En términos generales la obra puede leerse como un replanteamiento ofuscado del autor por reasignar una nueva ruta a su cordón umbilical a la manera en que Ulises

\footnotetext{
${ }^{1}$ Sontag, S. Against Interpretation and Other Essays. London, Penguin Books, 2013 [1996].

2 Bordieu, P. La dominación masculina. Barcelona, Anagrama, 2002, p. 6.

3 Barthes, R. The Pleasure of the Text. New York, Hill and Wang, 1975 [1973], p. 10.

4 Schrauwen, O. Arsène Schrauwen. Logroño, Fulgencio Pimentel, 2017.
} 
trama su aventura en el texto clásico. Esta vez, el cordón toma una ruta alternativa y en lugar de partir del vientre materno, pasa a través de la información genética para llegar a ese punto en el que Arsène Schrauwen — su abuelo paterno- sube a un barco hacia las colonias y así, hablar del relato memorial como una forma de volver a la vida, de resucitar con la autoficción.

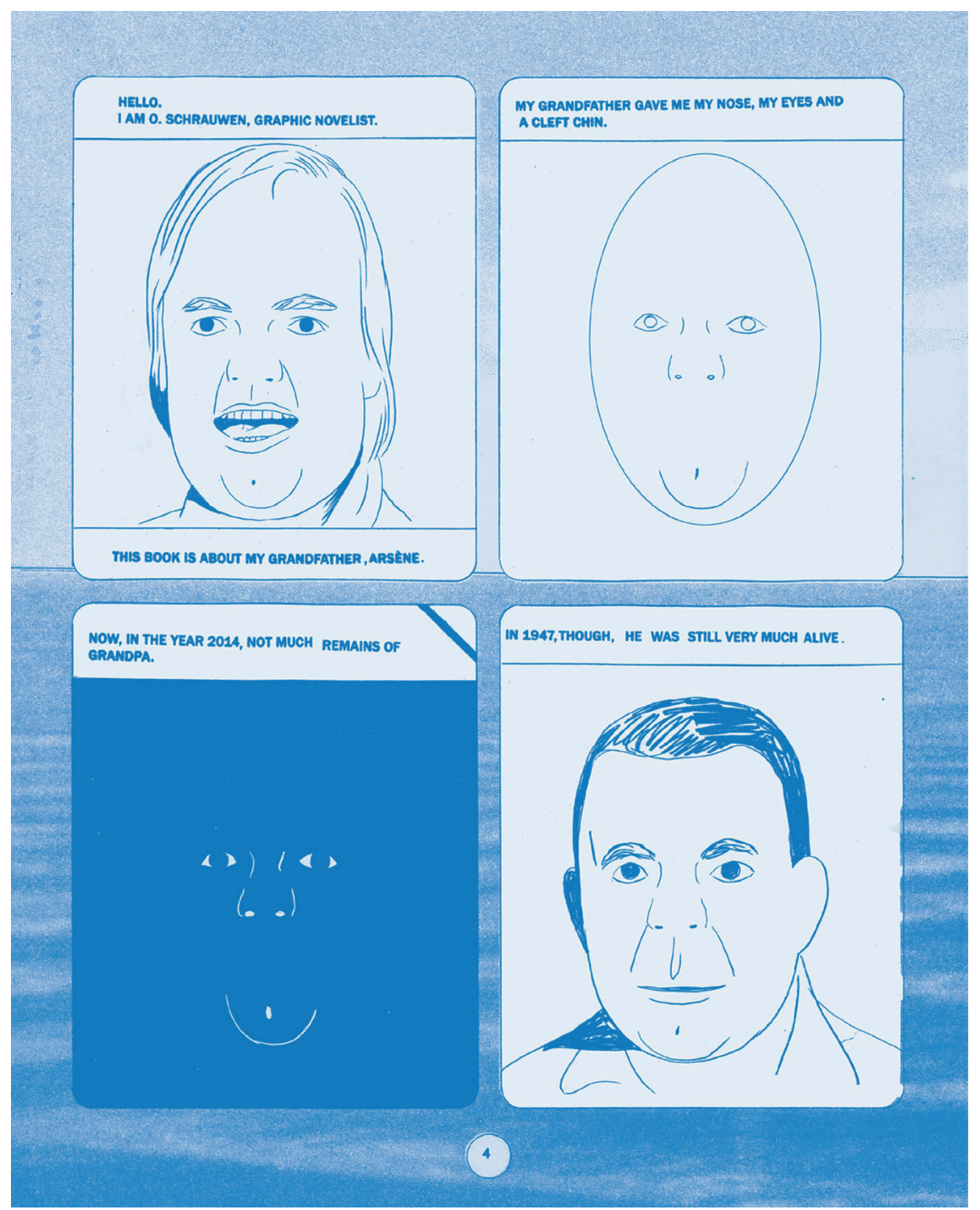

FIG. 1. Schrauwen, O. Arsène Schrauwen.

Logroño, Fulgencio Pimentel, 2017, p. 4.

En el año en que comienzan a narrarse las peripecias de Arsène, 1947, el nombre del protagonista, Arsène, es lo único que existe. Él es el hombre original, el Adán de los Schrauwen: ese astronáutico planeta del autor y por ende, de su visión del mundo. A priori el planteamiento puede parecer idealista, pero veremos si consigue construir esa ciudad que signifique «el epítome del pensamiento moderno, la cultura moderna 
y la convivencia moderna»..$^{5} \mathrm{Al}$ menos lo hará gracias a esa deformación de la ficción misma que esconde el género biográfico, o como lo describe Enrique Vila-Matas por medio de su personaje Mac: «Es extraño, ninguna generación quiere colocarse en los márgenes del Gran Camino, sino en el centro que ocupa el anterior. Deben de pensar que afuera no hay nada, y pensar esto los lleva a la larga a imitar y a repetir la aventura de aquellos a los que empezaron despreciando». ${ }^{6}$ Por lo tanto, revisar el pasado es recrearlo del modo en que nos hubiera gustado. Ahora, deformar es cosa del arte, pero las deformaciones, las protuberancias, los agujeros, giros y más giros, hasta la penetración de la narración artística, son un asunto erótico aparte que enlaza con el estilo campy en su afán por poner en cuestión la jerarquía estética y los formulados del buen gusto.

\section{Instinto queer}

En su deseo por deformar la historia de su antepasado - $\mathrm{y}$ su consiguiente herencia-, Olivier Schrauwen añade a la leyenda del conquistador un instinto queer que cuestiona el contrato social, los supuestos de verosimilitud y la veracidad histórica. Lo que distingue ese llamado instinto queer de otros lenguajes no convencionales y satíricos es la predisposición del texto para tomar entornos o contextos muy grandilocuentes - véase la construcción de una ciudad nueva en mitad de la selva inexplorada - y oníricos para parlamentar acerca del interés inherente al buen erotismo y al consumo artístico. La vida del joven forastero Arsène, quien persigue culminar una relación sexual pendiente con una mujer casada llamada Marieke, es un cuento chino, una pantomima cuya verdad consiste en recuperar los instintos y en confiar en la imaginación para autodesignar la identidad familiar y el mundo, en definitiva. La obstinación del protagonista por esa mujer y sus encuentros prohibidos entronca con la atmósfera de episodios extraordinarios que tienen lugar a su alrededor: todos ellos en estricto contacto con lo que la teoría queer señala relevante; es decir, con la diversidad sexual al margen del sesgo paternalista, los individuos de género fluido — con una especial atención a las mutaciones que se suceden en el plano físico-y las criaturas sobrenaturales.

\section{Erótica de la colonización}

Generalmente se considera que un texto es queer porque describe relaciones sexuales disidentes respecto a la moralidad de la época, así como por incluir cualquier elemento LGTBI. Sin embargo, esta no es la única representación del instinto queer al que se refiere el artículo. Sin duda, Arsène Schrauwen representa una colonización queer del

\footnotetext{
5 Schrauwen, O. Op. cit., p. 71.

${ }^{6}$ Vila-Matas, E. Mac y su contratiempo. Barcelona, Seix Barral, 2017, pp. 77-78.
} 
espacio, pero además es un cuestionamiento de la dominación masculina, como la denominaba Pierre Bordieu. ${ }^{7}$ Lo queer, o aquello que implica el término en sí, es decir, la libertad, se encuentra en medio de lo prohibido después de atravesar un mundo inexplorado. Uno tiene que cruzar la selva para llegar a un parque llamado «paraíso», en cuyas puertas aguarda otra sorpresa interesante, «formas extrañas y aleatorias que hallarían en un trapo carcomido de polillas». ${ }^{8}$ Lo queer es un horizonte que nunca acaba de alcanzarse, el fenómeno resultante de encaminarse hacia un destino, como dice José Esteban Muñoz. ${ }^{9}$ Por esta razón, el imaginario del descubridor, el fundador de un nuevo territorio que mira hacia los horizontes del ser y traspasa lo inexplorado, como en la filosofía de Edmund Husserl, ${ }^{10}$ representa de modo muy efectivo el propósito de este elemento. Digamos que las ficciones de exploración y conquista del espacio son un emblema de todo lo que toca el término queer y la falta de muros o barreras que limiten su campo de acción.

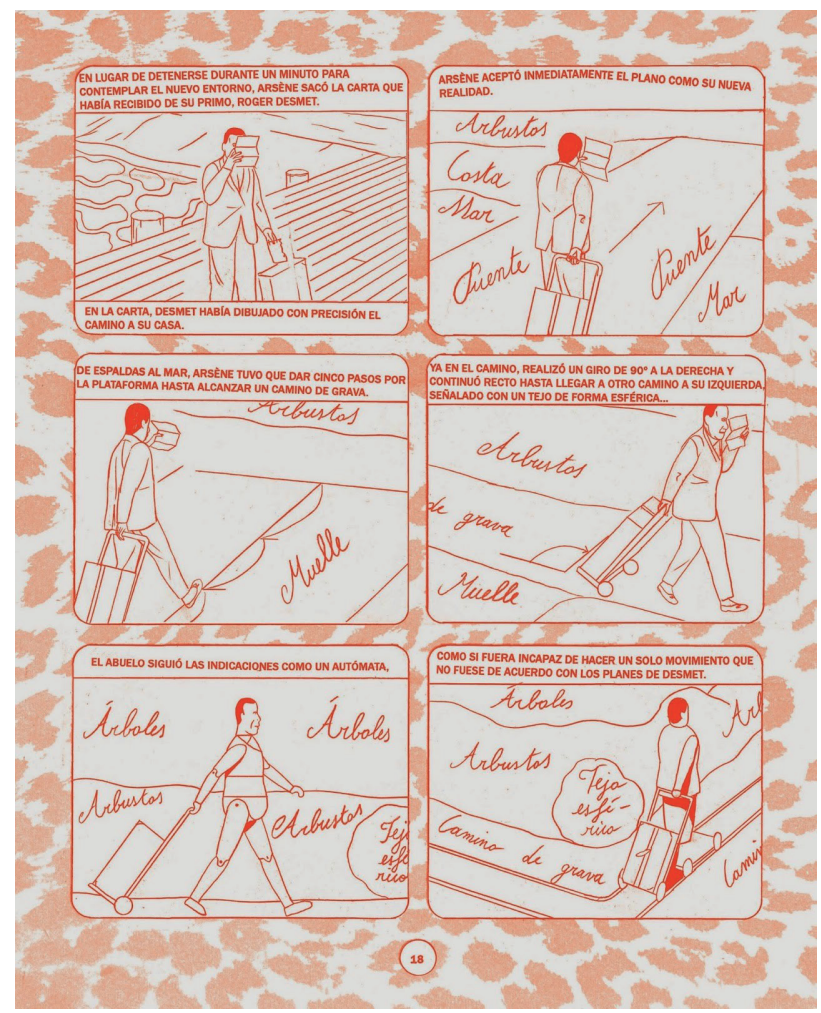

FIG. 2. Schrauwen, O. Op. cit., p. 18.

\footnotetext{
7 Bordieu, P. Op. cit.

8 Schraumen, O. Op. cit., p. 165.

9 Esteban Muñoz, J. Cruising Utopia The Then and There of Queer Futurity. New York, NYU Press, 2009, p.8.

${ }^{10}$ Husserl, E. La idea de la fenomenología: cinco lecciones. Madrid, Fondo de Cultura Económico, 1982.
} 
El protagonista «se adentraría pronto en lo desconocido», ${ }^{11}$ nos indica el narrador. Un agujero que sobrecogía a los colonos por culpa de las puras tinieblas que dentro de él se establecían. El inmutable Arsène desvía la mirada de los colonos — principales objetivos del escrutinio por parte del coronel Marlow en la novela canónica El corazón de las tinieblas, de Joseph Conrad $-{ }^{12}$ para dirigirla al territorio, «el verdadero incordio era la naturaleza salvaje de la colonia». ${ }^{13}$ Las coordenadas se mueven, son inestables e impredecibles, como en el surrealismo. Establecen lo que parece un juego o la imitación de los estados del sueño, en los que las distancias no existen o no pueden describirse. Los mapas que maneja Arsène siempre acaban resultando inútiles: son demasiado básicos o se llenan de hormigas, sus líneas se mueven confusas como el horizonte, etc. Parece que los instintos se hayan ocupado de dirigir la acción y vayan a cambiar de rumbo dependiendo del estado de ánimo del protagonista.

Alrededor de Arsène, los elementos inertes parecen cobrar una vida extraordinariamente descrita a nivel gráfico por el autor, en la que participan las rocas, las ramas de los árboles; cualquier cosa se convierte en imágenes sensuales y sugerentes. «En verdad se trataba de un juego muy idiota. En cualquier parte podía uno proyectar aquello que deseara». ${ }^{14} \mathrm{~A}$ nivel metaficcional esta premisa se parece a aquello que José Esteban Muñoz llama la imaginación política queer. ${ }^{15}$ En la novela, esa imaginación se materializa en la historia del abuelo Arsène, encargado de realizar el proyecto megalómano de su primo Roger Desmet: el enigmático arquitecto. También la construcción de un mundo narrativo - al que bautizar como «Libertad»- constituye un elemento potencialmente subversivo para ambos Schrauwen - autor y personaje- y recupera el sentido de la palabra queer aplicada a la política, como denuncia de las restricciones y las exclusiones sociales del heteropatriarcado. ${ }^{16} \mathrm{E} 1$ liberalismo queer, como lo describe David L. Eng, germina en la novela gráfica a partir del proyecto «Libertad», esa ciudad que proyectan edificar. Al mismo tiempo, es una paradoja que se llame «Libertad» a un sitio en el que los colonos rehuyen entrar porque está demasiado sumergido en la jungla. La dificultad de acceso y el hecho de que sea producto del afán colonizador del primo Desmet contrarían los supuestos detrás de la palabra libertad, y encumbran la ciudad más como un símbolo de la enfermedad del hombre moderno esclavo de las identidades impuestas en su sociedad. En su afán por esconderse, por ser libre encerrado en un espacio inhabitable e ilocalizable, el individuo frustrado inventa «Libertad»: que en su imaginación es similar al espacio de

11 Schrauwen, O. Op. cit., p. 6.

12 Conrad, J. Heart of Darkness. New York, W. W. Norton \& Company, 1988.

13 Schrauwen, O. Op. cit., p. 71.

14 Ibid., p. 67.

15 «[... queerness is instead a futurity bound phenomenon, a "not yet here" that critically engages pragmatic presentism». En Esteban Muñoz, J. Op. cit., p. 185.

16 ENG, D. L. The Feeling of Kinship: Queer Liberalism and the Racialization of Intimacy. Durham, N.C, Duke University Publishing, 2010, p. 11. 
sus sueños. En este sentido, la imaginación política queer aparece representada en la novela gráfica del autor belga como nunca podría haberse hecho: desde la frustración ideológica del patriarcado. Como en los textos modelo -El corazón de las tinieblas y Apocalypse Now Redux — ${ }^{17}$ lo que se ridiculiza es aquello que aparece fracasado y desquiciado: el ideario del colonizador, del settler — como se le llamaría en inglésen oposición al nativo o colono. En resumen, «the settler seems to be unsettled» o «aquel que se asienta parece estar poco estable». De hecho, tal y como puede comprobar el lector, los personajes mantienen relaciones inseguras y prohibidas entre ellos. Por ejemplo, Desmet, aunque casado con Marieke, mantiene una relación secreta con su amigo y ayudante Louis, por el capitán Louis Renault de la película Casablanca (1942) interpretado por Claude Reins. Ese personaje precisamente coprotagoniza junto a Rick Blaine (Humphrey Bogart) una de las escenas mas homoeróticas de la historia del cine. ${ }^{18}$ Visto así, Arsène también responde a la tipología de personaje de Rick Blaine en el film de culto: «un enamorado perpetuo que no por eso ha perdido su pulsión de aventurero solitario». ${ }^{19}$

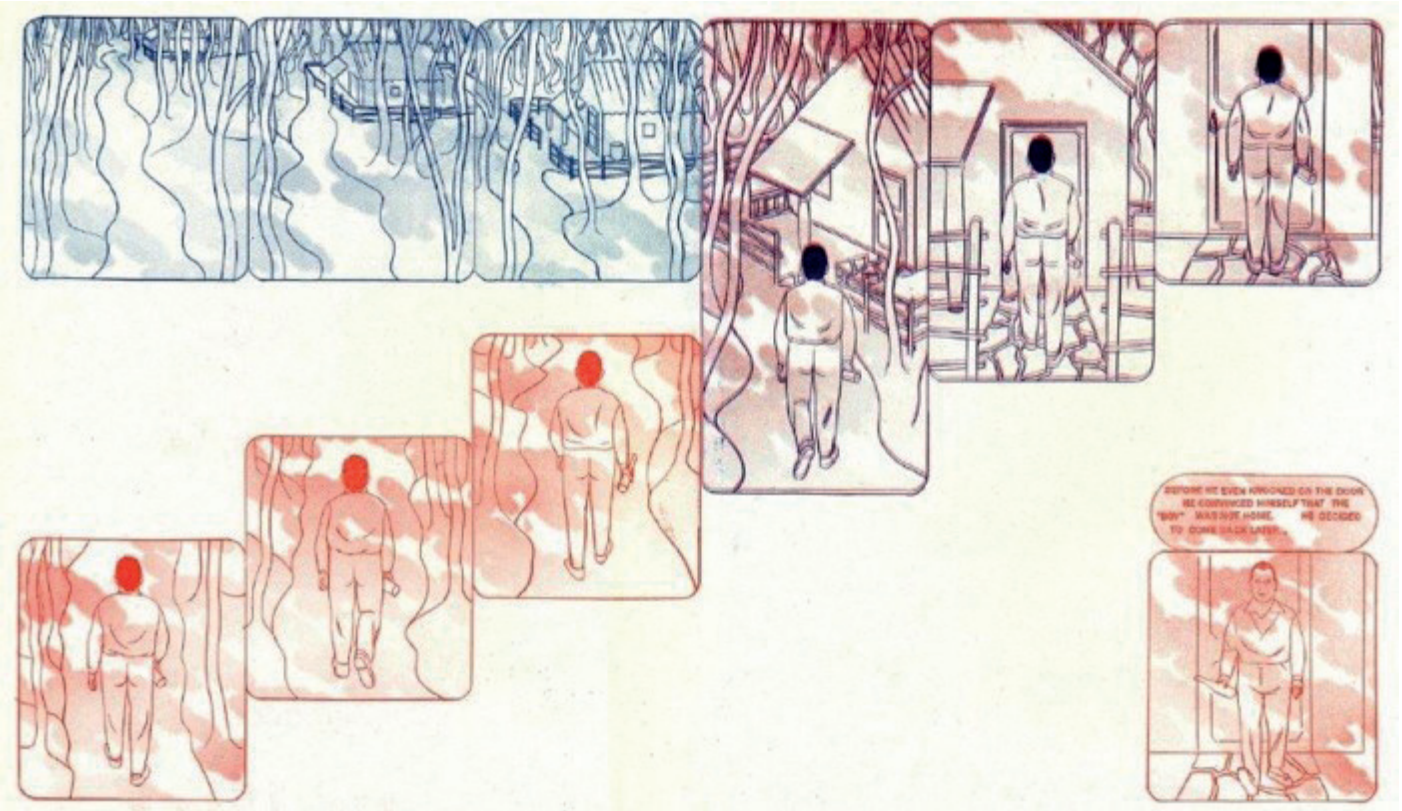

FIG.3. Schrauwen, O. Op. cit.,pp.52-53.

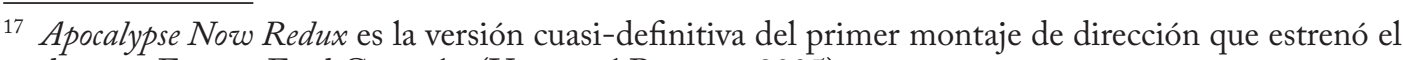
director Francis Ford Coppola. (Universal Pictures, 2005).

18 Fresán, R. «Una hermosa amistad», en Página 12 (21 de septiembre de 2003). Disponible en https:/www.pagina12.com.ar/diario/suplementos/radar/9-948-2003-09-21.html. El autor atribuye el origen de esta teoría al artículo de William Doneley "Love and Death in Casablanca» en McBride, J. (ed.). Persistence of Vision: A Collection of Film Criticism. Wisconsin, Wisconsin Film Society Press, 1968.

19 Idem.
} 
La decadencia de los valores impuestos por el heteropatriarcado para todos sus individuos hace evidente el patetismo del colonizador dándole la vuelta a la perspectiva supremacista sobre el nuevo mundo. Este patetismo se entiende también a través de la representación del falo. Arsène tiene pesadillas con la posibilidad de que los gusanos elefante - ese bicho cuya picadura produce una mutación de los miembros- le ataquen metiéndose en sus calzoncillos. Por eso pega su ropa interior al cuerpo con cintas de esparadrapo, para que no queden resquicios abiertos. En una de esas pesadillas, Marieke le va liberando poco a poco de esas pegatinas que recorren, ya no su cintura, sino sus genitales. En más de una ocasión, los genitales que tanto protege, por algún factor azaroso, quedan al descubierto y, por lo tanto, en peligro: «un pajarillo se abrió paso hasta la boca entreabierta de una flor, hundiendo el pico como una aguja en sus genitales». ${ }^{20}$ Toda esta simbología recupera las similitudes entre lo queer y la narrativa de la otredad, pues aquí también trata de descubrirse por medio de la adaptación a un nuevo territorio, criaturas, vegetación, personajes, reglas, etcétera: ese "pedazo infernal de jungla». ${ }^{21}$

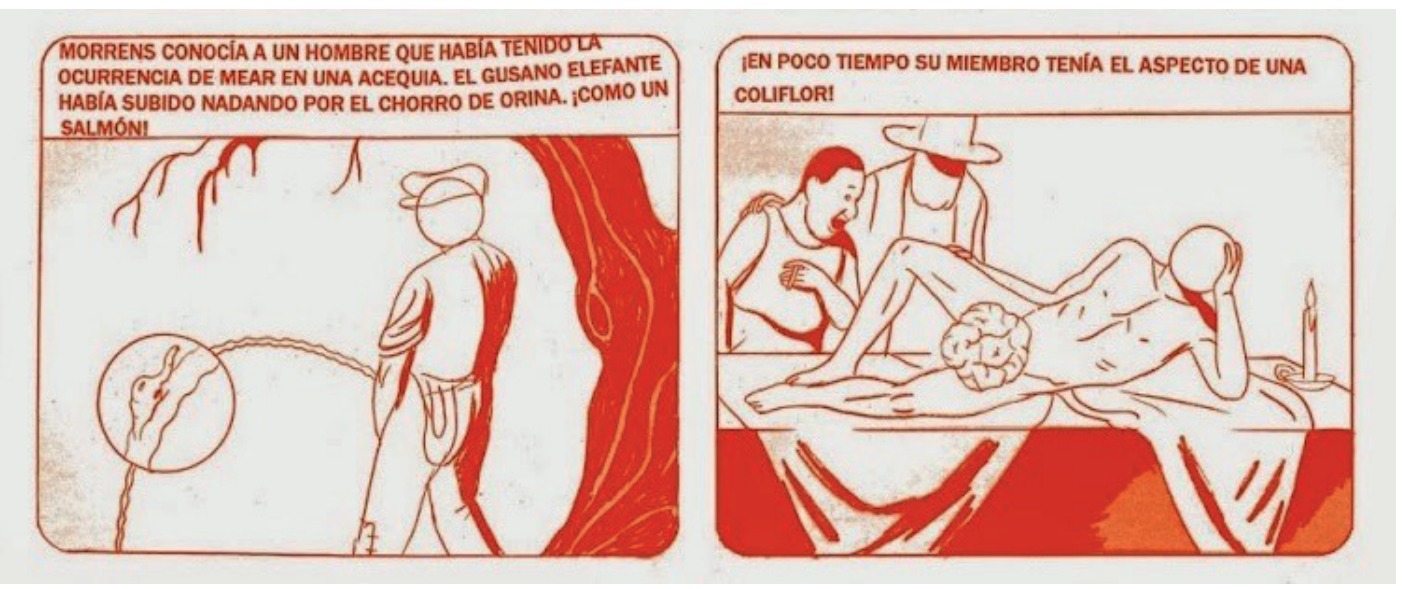

FIG. 4. Schraumen, O. Op. cit., p. 12.

Arsène revisita la poética del descubridor que, como el gold digger, penetra la jungla, le endiña, le chinga, le clava o ahoya su poder fálico. De esta fuente, oro por medio, beben las metáforas de estilos musicales como el hip hop o el punk rock mandando un apóstrofe contra las élites que controlan los recursos: «The excavation was a financial success / With artifacts of gold / The arrowheads went straight to the Smithsonian / The rest was melted down and sold.» ${ }^{22}$

${ }^{20}$ Schrauwen, O. Op. cit., p. 107.

${ }^{21}$ Ibid., p. 156.

22 «La excavación fue un éxito económico / con artefactos de oro / las flechas apuntaban al Smithsonian / el resto decidieron fundirlo y ponerlo a la venta». ("Dig», NOFX. Written by Mike Burkett (C) Universal Music Publishing Group). 
En la letra de una canción del grupo de rock My Morning Jacket vemos un eco del relato de Schrauwen, como si de una banda sonora original se tratara. La única diferencia es que aquí, en lugar de describir un acto erótico, es mas místico —otra de las posibilidades inherentes a la figura del imperio y del diseñador de dicho imperio.

Remnants of the empire, artifacts of love

Will I meet the designer, what will he dream up?

Remnants of the empire, gravity awake

What's held down to the ground next round goes into space

Raising up the empire, innocence and faith

What will hold you up and what will stand in your way?23

Parece que el verdadero Arsène se vaya creando de la nada; que este viaje iniciático le lleve por los secretos del exotismo, la rareza, lo abyecto y los deseos ocultos, pues las colonias están impregnadas de todo ello: eso que conforma el instinto queer. El instinto inunda el espacio narrativo, determina los hechos con tanta fuerza que arroja la verdad sobre quién es cada uno de los personajes, en contraste con los nativos - esa muchedumbre que adquiere la entidad de colectivo en base a la no representación de sus rasgos físicos y sus rostros redondeados-. Así se resuelve de manera gráfica y narrativa la falta de acercamiento al otro, mofándose de las políticas de la raza en medio del contexto de la colonización. El único nativo que se acerca un poco mas de lo habitual al protagonista es ese predicador que le avisa de algunos de los peligros que entraña la empresa en construcción y cuyas palabras toman la forma de un aliento maligno. No le vemos el rostro, pero sí le vemos articular frases en clave a través de su boca desdentada.

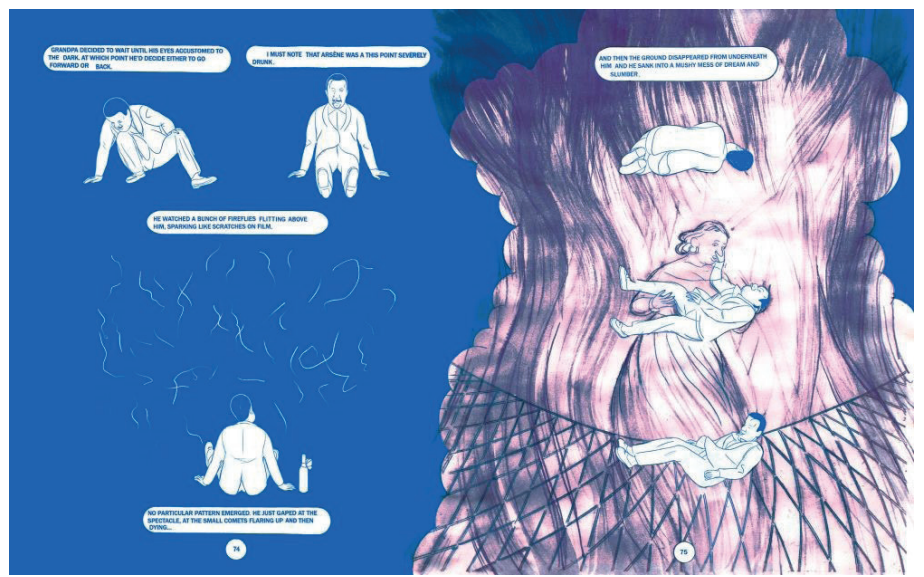

FIG. 5. Schrauwen, O. Op. cit.,pp. 74-75.

${ }^{23}$ «Restos del imperio, artefactos del amor / ¿Conoceré al diseñador? ¿Qué ideará? / Restos del imperio, gravedad recién descubierta / Aquello que sujetas un día, el siguiente día se lanza al espacio / Levantan un imperio, la inocencia y la fe / ¿Qué te sostiene y qué se interpone en tu camino?» («Remnants», My Morning Jacket. Written by James Edward Olliges, Jr. (C) BMG RIGHTS MANAGEMENT US, LLC). 
A un tiempo inverosímil y fantástico, el mundo de la historia se construye por medio de la narración gráfica a base de jugar con la polaridad de la risografía y su aspecto nostálgico, vintage y sostenible - pues originalmente las tintas están mezcladas en aceite de soja-. Este recurso permite mucha libertad creativa y notables matices visuales. Olivier Schrauwen los utiliza de modo que parezca que los colores luchan el uno contra el otro; otras, en cambio, hacen el amor. Tienen ritmo y significado recuperando las sensaciones de frío o calor, excitación o enfermedad, etcétera. La riso, como se la conoce coloquialmente, está ligada al contenido de la narración de manera indiscutible, no solo como juego perceptible, sino como base de representación de dos fuerzas ideológicas en contraste: el pensamiento occidental racionalista, en busca del amor romántico como fin último de la existencia; y el pensamiento colonial, enfermo de magia, extrañeza, ambigüedad, paroxismo y orgasmos: «vagaba por aquel pomposo palacio contemplando la decoración ridícula y excesiva». ${ }^{24}$

\section{Erótica y onirismo}

En el pasado, como lectores y críticos, nos preocupábamos por el problema de la veracidad —en inglés, reliability, que describe al autor como alguien en quien podemos confiar en mayor o menor medida - La escritura narrada, explicaba Roland Barthes, es esta que

[...] recompone por encima de la simultaneidad de los acontecimientos, un tiempo único y homogéneo, el del Narrador cuya voz particular, definida por accidentes reconocibles, cubre el develamiento de la Historia con una unidad parasitaria y da a la novela la ambigüedad de un testimonio que puede ser falso. ${ }^{25}$

En el espacio onírico de los sueños que es la jungla, en cambio, no nos plantearíamos la veracidad de lo ocurrido y tan pronto como lo hiciéramos, el autor, a través del texto, nos recordaría la única verdad: que no es verdad, pues sus leyes son parecidas a las de los sueños. Es «aquí», donde «termina la normalidad». ${ }^{26}$ Por eso, el narrador de Arsène, esa voz omnisciente que penetra a través de la psique del abuelo, se corresponde con el rastro de la memoria que el idealismo y la mentira humana manipulan en respuesta a una necesidad de superar lo execrable de algunas vivencias. En este caso, no son las propias vivencias las que se someten a revisión, pero sí las de alguien con quien el autor guarda un vínculo genético. Por lo tanto, el autor es consciente de que puede jugar con la información memorial, no la genética, puede desordenar el tiempo y, entonces, convertirse en un narrador que precede a la historia de su antepasado y por lo tanto, librarse de sus parecidos. No puede evitar

\footnotetext{
${ }^{24}$ Schrauwen, O. Op. cit., p. 138.

25 Barthes, R. Op. cit., pp. 86-87.

${ }^{26}$ Schrauwen, O. Op. cit., p. 155.
} 
representar los rasgos físicos que le unen a su antepasado, pero después se esconde tras el narrador: una voz que repite en medio del espacio onírico el nombre del protagonista como en esa escena del cuadro de Friedrich, Caminante sobre el mar de nubes (1817-1818).

La niebla, como muchos otros aspectos, juega un papel importante en pos de la deslocalización física y temporal acusada viñeta tras viñeta. No puede ignorarse que el cómic utiliza recursos gráficos muy efectivos, como los colores, la falta de profundidad y de detalles, los motivos vegetales, el caos secuencial, la caricatura o las figuras geométricas, entre otros, para lograr mimetizar los estados del sueño. Ese estado REM perpetuo en el que involucra al lector permanece al margen de la veracidad histórica excepto para ordenar una casuística en torno a la toma de poder de aquellos hombres de otro tiempo que siempre soñaron con la libertad. ¿Acaso alguien, aparte de Olivier Schrauwen, se planteó alguna vez qué hubiera pasado si estos hombres hubiesen terminado de edificar su «Libertad»?

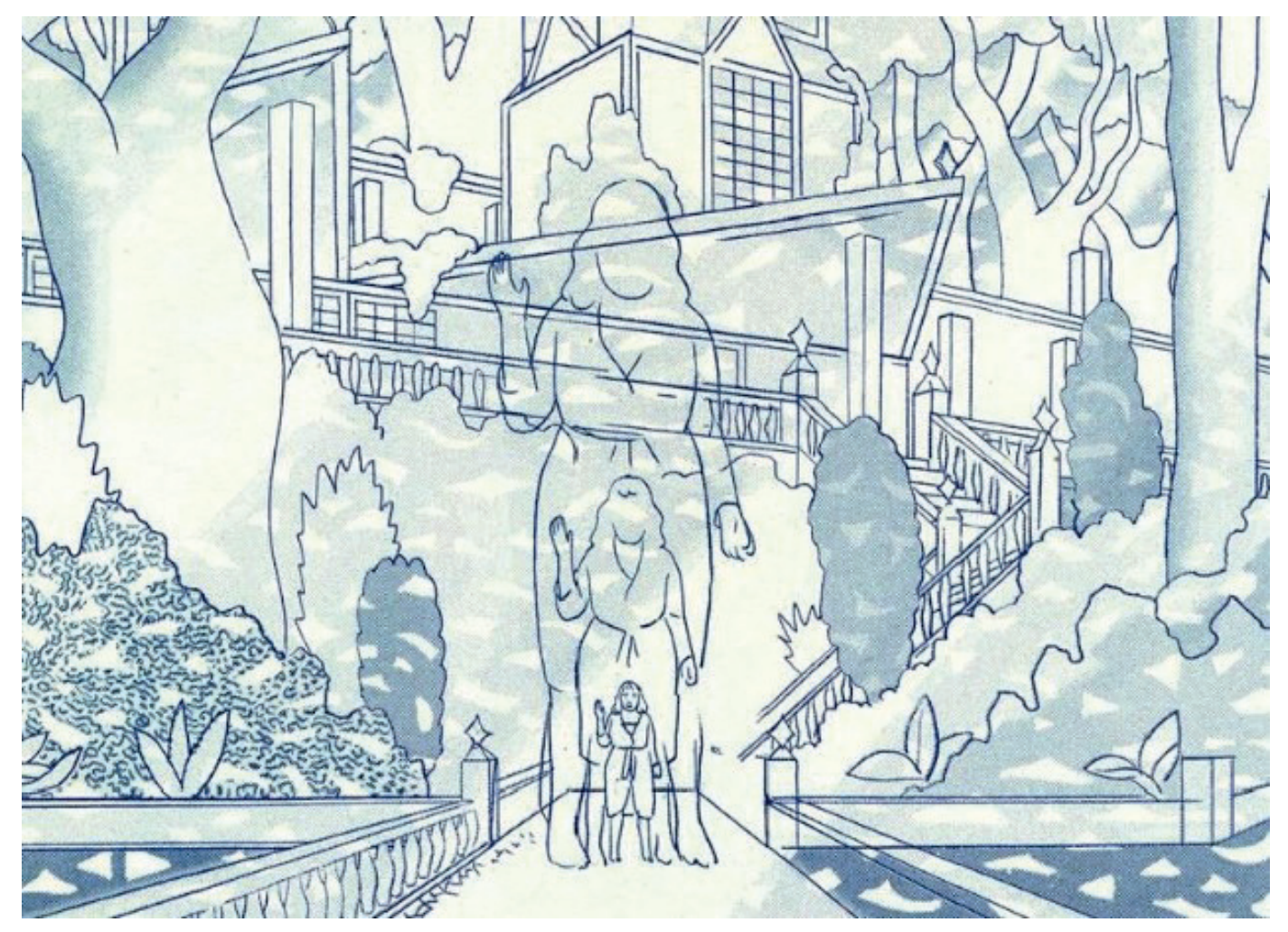

FIG. 6. Schrauwen, O. Op. cit., p. 26.

Al representar los sueños del abuelo Arsène, el resultado es una pantomima, un absurdo autoconsciente que deja sin esperanzas al lector y le pone en busca de otras distracciones. El estado de sueño revela el subconsciente y, por lo tanto, los deseos 
ocultos y los miedos. Nos corresponde a los lectores tomar una postura psicoanalítica o terapéutica y observar las calamidades que sufre el hombre moderno venido de la civilización y que se sitúa en medio de lo salvaje. En su mayoría, encontramos toques de humor o de un extraño terror que nos imposibilita confiar en el discurso y, por lo tanto, volver a la realidad, salvo porque el autor - en un afán por recuperar las obligaciones de la narrativa por entregas - nos pida abandonarla durante semanas entre un episodio y otro.

Arsène se preguntó a qué bufón se le habría ocurrido construir un parque temático belga en este emplazamiento tropical. Y por qué lo habría construido en la profundidad de la jungla, como avergonzado. Como esconde uno un artefacto sentimental en el fondo de un $\operatorname{armario.}^{27}$

Si aplicamos bien la erótica del texto, entendemos que el sueño tiene que ser aquella ciudad quimérica, ese Babel utópico en continua comunicación con lo divino, con el clímax, pues, a nivel de recepción artística, el texto del placer, tal y como indica Roland Barthes, «es un Babel autorizado». ${ }^{28}$ Para escribir un texto de placer hace falta un lugar de placer, de felicidad absoluta, y para llegar a este sitio, hace falta que medien las neurosis del creador, como dice Barthes: «el lema de todo escritor se lee así: podré no estar loco, no niego estar sano, pero neurótico sí que lo estoy». ${ }^{29}$ En la película Mauvais Sang (1986) de Leo Carax se establece un triángulo de deseo similar que atrapa al protagonista en la imposibilidad de poseer a la mujer que ama porque está casada con su jefe. Anne Marie le pregunta que por qué la mira tanto y él responde que hay que alimentar los ojos para soñar la noche. ${ }^{30}$

El placer de leer a Olivier Schrauwen se resume en su puesta en escena de las máximas aptitudes estéticas del arte secuencial, pero sin desdeñar la fuerza de una historia de siempre revisitada desde la sátira del antihéroe. Un antihéroe que, aunque anónimo para la humanidad, es el familiar directo del autor, su antepasado, su prototipo del hombre libre. Su erotismo también es muy atractivo en la pornografía velada que aparece en el plano lingüístico en forma de frases paródicas y grandilocuentes y, en el plano gráfico, con las insinuaciones de Marieke apareciendo aquí y allá y la libido alterada casi como en aquel sueño de una noche de verano de William Shakespeare durante el cual las parejas se confunden de amante y la ambigüedad reina en el aire. De hecho, Schrauwen también incluye un asno, como el famoso Bo-

${ }^{27}$ Ibid., p. 173.

${ }^{28}$ Traducido por la autora: «Thus every writer's motto reads: mad I cannot be, sane I do not deign to be, neurotic I am». Barthes, R. Op. cit., p. 4.

29 Schrauwen, O. Op. cit., p. 6.

30 «Il faut nourrir ses yeaux pour revéiller la nuit» (CARAX, Mauvais Sang Francia, Les Films Plain Chant / Soprofilms / FR3 Films Production / UNITE 3 / Centre National de la Cinématographie / Sofima 1986). 
ttom del texto de Shakespeare o El asno de oro o La metamorfosis de Apuleyo (siglo II d. C.) que se llamaba Lucio y estaba obsesionado con la magia. Desde su apariencia de animal, Lucio observa las calamidades que los hombres civilizados les hacen a sus esclavos. Al igual que en aquellos dos textos el elemento exótico precede a una inquietud distópica propia del fracaso de la plenitud sexual de los protagonistas. A los dos homosexuales les separa la puerta de la cárcel, mientras que entre Arsène y Marieke el amor es imposible, al tratarse ella de la esposa de su primo y al hecho de que la relación ilícita se vea constantemente puesta en duda. Su infructuosidad es inherente al erotismo, que se potencia de manera indirectamente proporcional a la satisfacción del acto sexual. Por eso dice Barthes que es la intermitencia lo que es erótico, la intermitencia de su piel a través de una transparencia, entre dos límites. Marieke aparece desnudándose o insinuando partes de su piel al joven Arsène en multitud de ocasiones eróticas.

En la intimidad de la habitación, Arsène representó una pequeña pantomima. El desarrollo de aquella pieza, ejecutada entre calambres y un extraño mutismo, habría desconcertado a cualquier espectador. Decididamente tenía que ver con Marieke. Con qué audacia la abordaba para arrojarla en la cama y colmarla de caricias y besos. ${ }^{31}$

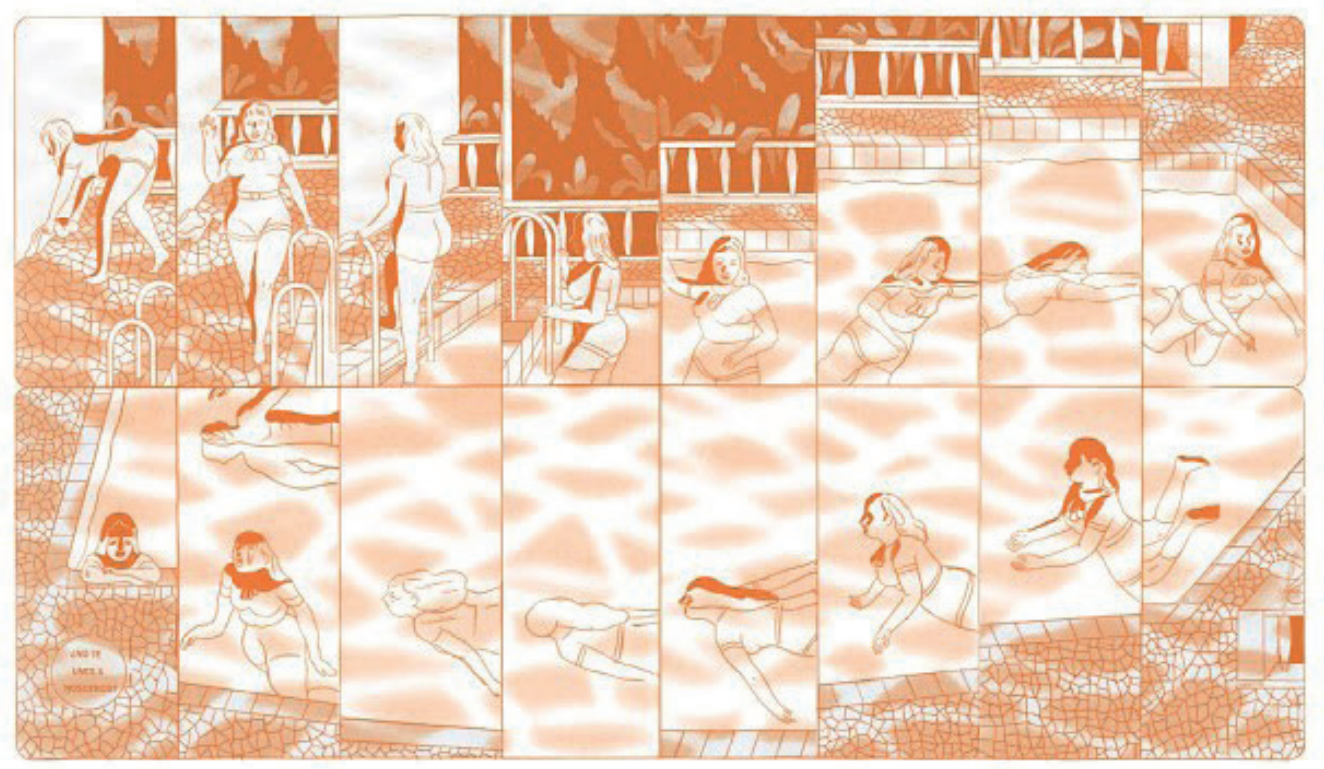

(

(i)

FIG. 7. Schraumen, O. Op. cit., pp. 26-27.

${ }_{31}$ Schraumen, O. Op. cit., p. 139. 


\section{Escenas campy}

Camp o campy es un adjetivo anglosajón que designa un tipo alternativo de representación cultural que se describe como exagerada, que exhibe un comportamiento teatral o que es afeminada. En su novela The Autograph Man, Zadie Smith describe a un personaje de este modo: «Era camp en el sentido estricto pues ninguno de sus gestos era útil o necesario». ${ }^{32} \mathrm{Si}$ bien nada es accesorio en su presentación, esa autoparodia de lo biográfico, hasta de la figura del autor y la novela gráfica como género «de culto», son elementos imprescindibles para entender el grado en que puede designarse como camp. El autor ha indicado en algunas entrevistas que la seriedad del género a veces contribuye a que la atención del lector se disipe y no se capten los detalles, la ironía y el sinsentido. La exageración y el absurdo pues, como elementos camp, privilegian una mejor recepción del texto de acuerdo a esta premisa. La búsqueda de la artificialidad del entorno natural es indispensable para recuperar nuestra mirada de nuevo. De algún modo plantea que lo natural, entendido como la representación fiel o mimética, sería demasiado convencional para fijarse en ella mientras se cuenta una historia. La importancia del estilo camp, exagerado, fuera de la cordura, extravagante y confuso, contribuye a que el lector acuda a la erótica del texto de manera inconsciente. El libro comprende el placer del texto, lo cuida y lo intensifica.

\section{El pervertido}

Todo es tan camp, que ni la naturaleza es natural: solo el reflejo de los lúbricos sueños de los protagonistas.

El secreto muchas veces está en algo que el lector capta a primera vista y que también se ha mencionado anteriormente; es decir, la proyección de un texto convencional y hasta ampuloso - venido de modos de descodificar un tipo de narración «vintage», si así puede llamarse - contra un entorno visual fragmentario, indeterminado, experimental, chocante y pervertido. Porque este texto pervierte, en el sentido en que define la RAE semejante acción, ya que «altera el buen gusto o las costumbres que son consideradas como sanas o normales, a partir de desviaciones y conductas que resultan extrañas».

En el suspense del autor belga, observamos un poder del erotismo sucio y feo, de todo lo crappy traducido en un código de heroísmo o carismático; empezando por el feo abuelo del autor que viste como un abuelo, aunque la narración esté inspirada en sus años de su juventud. El viejo verde no deja de mirar a Marieke a través de cualquier resquicio que quede entre ambos en un hambruna voyeur por ver el sexo de la protagonista, por penetrar en sus secretos como a través de la jungla salvaje. Su hambre pa-

\footnotetext{
32 Traducción de la autora. Sмiтh, Z. The Autograph Man. London, Penguin Books, 2003, p. 367.
} 
rece asemejarse, de nuevo, a la recepción del texto, debido a que se parece al deseo de saber y conocer más de los lectores. Lo que ocurre es que el protagonista jamás queda saciado, como explicábamos en la erótica del mensaje, como tampoco lo hace el lector persiguiendo curioso hasta el fin. La mente del lector queda, por tanto, pervertida, encerrada en la persecución del orgasmo de esas mentes que los hombres de la acción creen poder controlar. Sin embargo, no tienen tales poderes y los que les quedan los van perdiendo por el camino o por la bragueta, ya sea seducidos por criaturas antinaturales que les sodomizan en lo alto de las ramas de los árboles o amenazados por el miedo a lo desconocido.

La perversión tiene lugar desde el inicio, con las colosales paperas del viejo Morrens que «tenía párpados caídos y, lo que tenía bastante guasa, unos labios inusualmente grandes. El modo en que sus labios acariciaban el borde del vaso era casi obsceno». ${ }^{33}$ El viejo, en ese primer momento desconocido, guarda sus rasgos mas exagerados, más campy, para reaparecer como el padre de Marieke al final de la narración no sin dejar de insinuarse a nuestro protagonista.

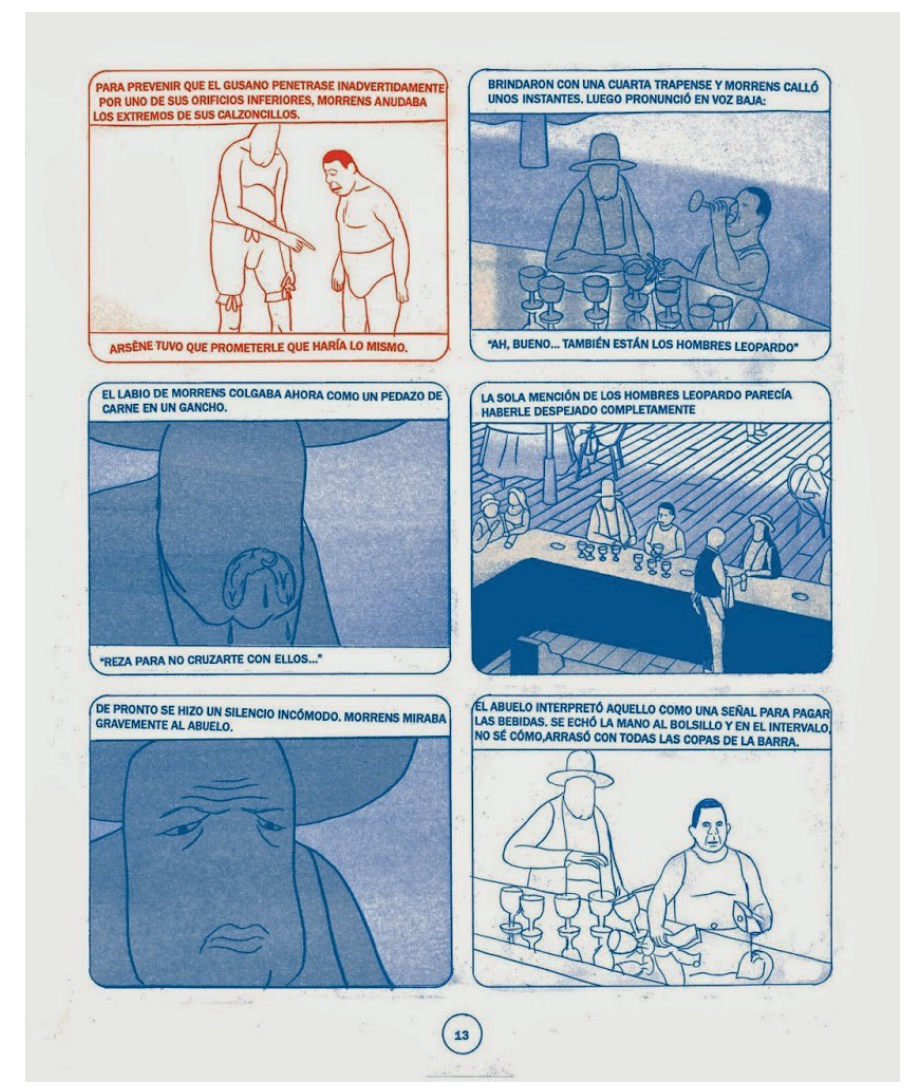

FIG. 8. Schraumen, O. Op. cit., p. 13.

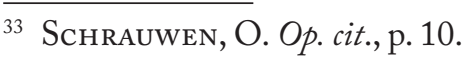


Otro personaje y escena absurda e inservible a la historia, pero muy efectiva en el plano erótico y el imaginario queer, es la amenazante presencia del chaval, ese colono que es mandado por su primo Desmet a dar sus servicios a Arsène. Estando este demasiado concentrado en sus temores y pesadillas dentro del bungaló, el abuelo es incapaz de relacionarse con ese ser que espera sus órdenes allí fuera, como un perro fiel, que le lleva alimentos y la manutención básica para la jungla. Sin embargo, el lector está con Arsène y desconfía de la presencia de alguien a quien jamás ha visto antes que nos espía entre la espesura floral e incluso trata de envenenar al viejo con unos huevos de avestruz caducados.

Otras escena camp que sirve de ejemplo es aquella en la que unas criaturas moteadas hipnotizan a sus víctimas: «Ninguna máscara de carnaval habría podido igualar aquellos rasgos grotescos. Cada músculo parecía moverse independientemente, como si un nido de culebras viviera bajo su piel». ${ }^{34} \mathrm{Y}$, por último, no son nada atractivas tampoco las mutaciones que invaden el cuerpo de los enfermos de esa extraña epidemia que está teniendo lugar y que Arsène asocia al bicho acuático conocido como gusano elefante.

\section{Erótico y esotérico}

Schrauwen - nieto- es un autor que se identifica con ese colectivo artístico conocido como el «small-press world» o la cultura editorial alternativa, en la cual los artistas distribuyen y manufacturan el soporte de representación artística. Esto, aunque difícil de defender en el vasto mercado editorial por su dificultad de competir con los grandes sellos, proporciona a los autores y creativos una libertad como ninguna.

Desde su libertad creativa se entiende aún mas la dimensión campy del signo gráfico y lingüístico de este cómic de Schrauwen, pues, tal y como lo describe Susan Sontag, su esencia es «el amor a lo no natural: al artificio y la exageración. [...] lo camp es esotérico: tiene algo de código privado, de símbolo de identidad incluso, entre pequeños círculos urbanos». ${ }^{35}$

Tanto el contexto de la autopublicación como el recurso de la autoficción y el lenguaje que utiliza la obra resultan esotéricos y herméticos para el lector, descifrables en un paradigma del absurdo y surrealismo, aunque parte activa también en la creación de ese universo propio que le brindan los recursos creativos que le ofrece el conocido small press. De nuevo, el universo de Arsène Schrauwen se configura a partir de un lenguaje propio. Veamos como ejemplo las «trapenses» que aparecen repetidamente a lo largo de la narración. Por supuesto, nadie utiliza este sustantivo cuando dice que se quiere beber

\footnotetext{
${ }^{34}$ Ibid., p. 203.

35 Sontag, S. Op. cit., p. 355.
} 
una cerveza, y en momento alguno del cómic se aclara qué es una trapense ni por qué llamarlo así cuando puede decirse cerveza. Este fenómeno se conoce como metonimia o trasnominación y consiste en la sustitución de un término por otro con el que guarda una relación de inclusión: en este caso la cerveza toma el nombre de la orden religiosa que las fabricaba. Pero, ¿jpor qué nombrarlas de semejante modo? Pues bien, los trapenses surgen de la reforma cisterciense del siglo xviI en la abadía de Trapa, Francia. Su nombre completo es la Orden Cisterciense de la Estricta Observancia y lo de su estrictez se debe a que es la primera orden sujeta a la orden de San Benito o las nuevas leyes de ordenación de la vida monástica, después de percibir la relajación que se estaba produciendo en algunos monasterios. Por lo tanto, estos datos guardan relación con la trama del cómic, pues sacan a relucir otro elemento de poder del hombre, el religioso, que gobernaba los motivos de colonización de otro pueblo y que probablemente se utilice para satirizar parte de la cristianización o ese arma ideológica de los invasores, quienes se creían destinados a liberar a los colonos de sus culturas para imponerles la propia. Las trapenses en el cómic Arsène Schrauwen simbolizan esa parte ideológica no mencionada. Precisamente en la escena del bar lleno de colonos ebrios en el que irrumpe el abuelo mientras todos se quedan en silencio, se revela, a modo de sátira, cómo se perpetúa el poder del hombre blanco occidental en las colonias. Las trapenses, como otras drogas, forman parte del collage surrealista que toma los estados del sueño como epítome de la duda, la subjetividad, lo verificable, la verosimilitud y la historia.

No solo las trapenses ilustran el tipo de código libre que configura el universo de Schrauwen. También lo son los gusanos elefantes, parásitos inventados que atacan los genitales masculinos y a los que Arsène teme por encima de todos los peligros de su expedición, quizá por su carácter castrador e inhibidor de la hegemonía masculina y política prometida, y los hombres leopardo, o «el chaval», porque es un nuevo modo de denominar al sujeto sin identidad que tiene la discreta misión de servir al abuelo Arsène. Hay otra serie de ejemplos no asociados al signo lingüístico, pero sí al gráfico, y que también forman parte de aquello que distingo como código libre de la obra. Por ejemplo, el avestruz, el asno o los rostros circulares y vacíos de los hombres colonos que rodean la misión de Desmet.

La necesidad de describir lo camp, por ser uno de los recursos de autorización del llamado instinto queer, se hace evidente de manera significativa en el personaje de Desmet, el primo del abuelo, quien diseña el proyecto arquitectónico y urbano de la ciudad proyectada. Es él quien también diseña esos trajes insólitos para la inauguración del sitio. Sus diseños, semejantes entre sí, enfatizan el concepto de la creación artística como proceso artificioso y ambicioso. Por cierto que determinados accesorios de la vestimenta masculina se postulan como remanentes de la caracterización varonil puesta en peligro con cada viñeta. Así sucede en la escena en la que Marieke le coloca un sombrero al abuelo y le dice: «¡Oh, es genial! ¡Muy varonil!». ${ }^{36}$

36 Schrauwen, O. Op. cit., p. 144. 


\section{Conclusiones}

Después de recuperar un parte de la historia de su antepasado, es interesante revelar que existe una relación entre los aspectos de memoria, autoficción y los del deseo erótico explícito entre los personajes. Por supuesto, como en toda obra de calidad literaria, en el cómic de Schrauwen la forma va ligada al contenido de manera indisoluble, lo cual explica la estrecha relación entre ambos términos, sobre todo en un medio en el que la forma del texto - aquí demostrando las capacidades artísticas de la risografía - juega un papel clave. Bajo el gobierno que el lenguaje visual ejerce en la historieta, Arsène Schrauwen habla de lo queer al anteponer la extravagancia camp a la clásica dominancia masculina. Los antihéroes sucumben ante el erotismo del espacio, la narrativa del conquistador y el relato absurdo y camp que exagera los giros del relato, hasta los rasgos de los personajes. El autor construye una etnografía extravagante y camp con la que consigue salir de ese círculo de significación, a pesar del «falonarcisimo» de la historieta. ${ }^{37}$

Los deseos de colonizar acaban con un desvanecimiento del clímax orgásmico nunca alcanzado o el fracaso de la megalomanía del hombre. Esa derrota de la dominación masculina se hace tan patente en el personaje del abuelo como en Desmet, creador omnipresente que mantiene una relación homosexual secreta aunque está casado al mismo tiempo con Marieke. Desmet juega a desconcertar al lector y, por tanto, es huidizo, desagradable e imposible de trazar salvo porque pertenece al arquetipo del inventor loco, algo quijotesco, abrasado en el fuego del delirio creador y obsesionado con mantener el control en un territorio que considera de su propiedad. Igual que el personaje cervantino, los personajes, ebrios de trapenses, ven monstruos donde hay molinos; es decir, confunden la realidad con la ficción. Su idealismo fantasioso les convierte en héroes fallidos, aunque simpáticos, cuyo anticlímax no es otro que una relación sexual no consumada y el fracaso de la construcción de «Libertad», una ciudad como la «Utopía» de Tomás Moro, aunque con más disfraces y glamour camp. De hecho el ideólogo de «Libertad», y aquí viene la gran ironía de la obra, es encarcelado.

Sin duda la construcción mental de una gran obra humana también es erótica en puridad, para entender mejor a qué se refiere Sontag en su famoso texto. El erotismo precede, anuncia, engalana el acto amoroso deseado en la imaginación del poeta y del lector, hasta hacerle asumir que solo en el registro de la ficción es donde verdaderamente estos dos agentes pueden vencer el placer negado.

37 El término «falonarcisista» lo utiliza Bordieu para designar la cosmología androcentrista o la hegemonía de la masculinidad para los criterios de juicio. Bordieu, P. Op. cit., p. 8. 


\section{BibLiografía}

Barthes, R. The Pleasure of the Text. New York, Hill and Wang, 1975 [1973].

Bordieu, P. La dominación masculina. Barcelona, Anagrama, 2002.

Conrad, J. Heart of Darkness. New York, W. W. Norton \& Company, 1988.

Doneley, W. «Love and Death in Casablanca», en McBride, J. (ed.). Persistence of Vision: A Collection of Film Criticism. Wisconsin, Wisconsin Film Society Press, 1968.

Esteban Muñoz, J. Cruising Utopia The Then and There of Queer Futurity. New York, NYU Press, 2009.

Fresán, R. «Una hermosa amistad», en Página 12 (21 de septiembre de 2003). Disponible en https://www.pagina12.com.ar/diario/suplementos/radar/9-948-2003-09-21.html

Hussert, E. La Idea de la fenomenología: cinco lecciones. Madrid, Fondo de Cultura Económico, 1982.

L. ENG, D. The Feeling of Kinship: Queer Liberalism and the Racialization of Intimacy. Durham, N.C, Duke University Publishing, 2010.

Schrauwen, O. Arsène Schrauwen. Logroño, Fulgencio Pimentel, 2017.

Sмiтн, Z. The Autograph Man. London, Penguin Books, 2003.

Sontag, S. Against Interpretation and Other Essays. London, Penguin Books, 2013 [1996].

Vila-Matas, E. Mac y su contratiempo. Barcelona, Seix Barral, 2017. 